\title{
DOUBLE REDUCTION AT THE MID LOCUS IN LYTHRUM SALICARIA
}

\author{
VIVIANE C. FYFE \\ Department of Genetics, University of Cambridge
}

Received 22.i.53

\section{INTRODUCTION}

THE gametic output from polysomic organisms of various genotypes can be expressed in terms of a single parameter, namely, the frequency of double reduction. This is the frequency with which a gamete receives two alleles derived from the same chromosome at meiosis.

The term "double reduction" was first introduced by Darlington (1929) and defined as a case " where both chromatids of one chromosome pass into the same nucleus at the second telophase". This offered an explanation for the appearance of one recessive in a progeny of 137 from a reciprocal cross between a triplex and nulliplex Dahlia obtained by Lawrence (I929). Similar results had been obtained by Blakeslee, Belling and Farnham (1923), who got 2 per cent. recessives from a triplex Datura when backcrossed to the recessive, and I per cent. when crossed to the simplex genotype. These early workers, however, expected to find an abnormal number of chromosomes in the recessives. Blakeslee et al. examined their recessives but found the numbers to be normal.

Haldane (I930) pointed out that though the passing of two identical chromatids to the same gamete in a diploid organism implied an abnormal chromosome complement in the resulting zygote, this was not the case in polyploids. He calculated the ratios to be expected if the eight chromatids of a tetraploid were distributed at random into the gametes. In the mating between a triplex and a nulliplex, one recessive in 28 could be expected on this hypothesis. Darlington (193I), however, showed that cytologically there were a number of restrictions to Haldane's theory, and concluded that intermediate conditions between random segregation of chromatids and diploid segregation were to be expected, and had in fact been observed by Lawrence.

In four crosses involving one triplex with four different nulliplex, Lawrence (1935) observed double reduction at the $Y$ locus in tetraploid Dahlia. He obtained 7 recessives out of 385 plants and explained this as "probably due to chromatid segregation". At none of the three other loci studied did double reduction appear. It should be noted, however, that it was never certain that a triplex was involved in the matings.

An important contribution was made by Mather (1936) when he 285 
pointed out that "the amount of double reduction is a function of the cross-over distance between the locus and the spindle fibre," and, therefore, will vary from locus to locus. This has since been demonstrated in Lythrum salicaria by Fisher (1949), who gave preliminary estimates of the frequency of double reduction at the purple/pink locus as 6.5 and at the short/non-short locus as 2.5 . These estimates were obtained incidentally in an attempt to ascertain the frequencies of the eleven modes of gamete formation now known to be characteristic of linkage in tetrasomic organisms. They are based on the proportion of duplex plants obtained from simplex parents backcrossed to the recessive long-styled pink. This method involves making a second backcross to determine the genotype-whether duplex or simplexof the dominant offspring.

An estimate based on the proportion of recessives obtained on backcrossing the triplex genotype is more direct, requiring no second backcross and can, in consequence, be based on large numbers with greater facility. This latter method has been used to estimate the frequencies of double reduction both in pollen and ovules at the mid locus in the work described here. It should be noted that for an estimate at the short locus this method cannot at present be used, since a triplex short could only be obtained by illegitimate fertilisation. All attempts to obtain such a plant have so far failed.

\section{DOUBLE REDUCTION IN OVULE FORMATION}

When Fisher and Mather (1943) established the existence of polysomic inheritance in $L$. salicaria, they did so by backcrossing to the long-styled form, I6 Shorts and 12 Mids obtained from a cross between a Short and a Mid, both of which had one and the same dominant mid allele. The resulting progenies showed that one Short was nulliplex for mid, I I were simplex and 4 duplex; 8 of the Mids were simplex, 3 duplex and I plant, $\mathrm{M}_{40} \cdot 2 \mathrm{~F}$, gave no Longs out of $4 \mathrm{I}$ non-shorts. This plant was tested the next year with a progeny of 1034 (Fisher, 1944). It gave 22 Longs out of a total of 1075 in two years, and must, therefore, be a triplex and have arisen by double reduction. This first evaluation of the frequency gave an estimate of $8 \cdot 19 \pm \mathrm{I} \cdot 73$ per cent.

In an attempt to obtain a Short triplex for mid, two of the Shorts that were found to be duplex for mid were crossed to a simplex Mid $\left(\mathrm{Ss}_{3} \mathrm{M}_{2} \mathrm{~m}_{2}=\mathrm{s}_{4} \mathrm{Mm}_{3}\right)$, and twenty-five Shorts obtained from this cross were tested in 1945. The twenty-five progenies are given in table I, from which it will be seen that five plants triplex for mid were identified. Fifteen of these plants were again backcrossed, this time to pale pinks to provide triplex pales and data on the linkage of the Short and purple loci. The test progenies grown in 1946 are given in table 2, in which the Long, Mid and Short segregations alone are given. There is evidence that some stray pollen was present from the 
2 Mids that appeared in the progeny of the nulliplex plant. The data from the four triplex plants will nevertheless be included in our estimate of double reduction, for, as will be shown later, a small percentage of foreign pollen does not alter the estimate appreciably. The fifth triplex plant was crossed to the triplex $\mathrm{Mid}, \mathrm{M}_{40} \cdot{ }_{2} \mathrm{~F}$, in an attempt to obtain both Shorts and Mids quadruplex for mid. In 1947 eleven

TABLE I

Test progenies from 25 Shorts (1945)

\begin{tabular}{|c|c|c|c|c|c|}
\hline Genotype & Plant & L & $\mathbf{M}$ & S & Total \\
\hline Nulliplex & $\mathrm{S}_{44 \cdot 2 \mathrm{G}} 5$ & 105 & $\ldots$ & 89 & 194 \\
\hline \multirow[t]{2}{*}{ Simplex } & 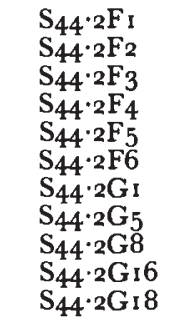 & $\begin{array}{l}30 \\
39 \\
47 \\
38 \\
52 \\
39 \\
41 \\
55 \\
30 \\
57 \\
36\end{array}$ & $\begin{array}{l}63 \\
62 \\
47 \\
60 \\
55 \\
43 \\
57 \\
62 \\
51 \\
5^{1} \\
4^{2}\end{array}$ & $\begin{array}{r}105 \\
97 \\
107 \\
101 \\
95 \\
114 \\
102 \\
84 \\
123 \\
88 \\
84\end{array}$ & $\begin{array}{l}198 \\
198 \\
201 \\
199 \\
202 \\
196 \\
200 \\
201 \\
204 \\
196 \\
162 \\
\end{array}$ \\
\hline & Total . & 464 & 593 & 1100 & $2 \times 57$ \\
\hline \multirow[t]{2}{*}{ Duplex } & 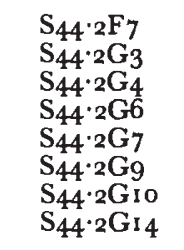 & $\begin{array}{r}12 \\
14 \\
8 \\
13 \\
16 \\
21 \\
18 \\
10\end{array}$ & $\begin{array}{l}94 \\
90 \\
91 \\
85 \\
68 \\
71 \\
85 \\
83\end{array}$ & $\begin{array}{r}95 \\
96 \\
102 \\
105 \\
114 \\
109 \\
98 \\
96\end{array}$ & $\begin{array}{l}201 \\
200 \\
201 \\
203 \\
198 \\
201 \\
201 \\
189 \\
\end{array}$ \\
\hline & Total & 112 & 667 & $8 \times 5$ & $\times 594$ \\
\hline \multirow[t]{2}{*}{ Triplex } & $\begin{array}{l}\mathrm{S}_{44 \cdot 2} \mathrm{G}_{2} \\
\mathrm{~S}_{44 \cdot 2} \cdot \mathrm{G}_{11} \\
\mathrm{~S}_{44 \cdot 2 \mathrm{G}_{2}} \\
\mathrm{~S}_{44} \cdot 2 \mathrm{G}_{3} \\
\mathrm{~S}_{44} \cdot 2 \mathrm{G}_{17}\end{array}$ & $\begin{array}{l}2 \\
1 \\
4 \\
4 \\
1\end{array}$ & $\begin{array}{l}95 \\
87 \\
89 \\
93 \\
88\end{array}$ & $\begin{array}{l}105 \\
111 \\
106 \\
100 \\
109\end{array}$ & $\begin{array}{l}202 \\
199 \\
199 \\
197 \\
198\end{array}$ \\
\hline & Total . & 12 & 452 & $53 x$ & 995 \\
\hline
\end{tabular}

Shorts and twelve Mids obtained from this cross were backcrossed to Longs and progenies grown in 1948 . It will be seen from the squareroot chart in fig. I that five Shorts and six Mids triplex for mid were found.

The possibility that the eleven plants classified as triplex were not all that should have been so classified, i.e. that one or more had been classified as quadruplex, may be examined as follows. The number of Long progeny observed from nearly equal progenies with the same 
frequency of double reduction, should be distributed nearly in a Poisson Series. If $m$ is the expectation, then the frequency of cases in which none occur will be $e^{-m}$, and the frequency of cases with at least one

TABLE 2

Test progenies from ${ }_{15}$ Shorts (1946)

\begin{tabular}{|c|c|c|c|c|c|}
\hline Genotype & Plant & $\mathbf{L}$ & $\mathbf{M}$ & $\mathbf{S}$ & Total \\
\hline Nulliplex & $\mathrm{S}_{44} \cdot{ }^{2} \mathrm{G}_{15}$ & $4^{8}$ & 2 & 63 & 113 \\
\hline \multirow[t]{2}{*}{ Simplex } & $\begin{array}{l}\mathrm{S}_{44 \cdot 2 F_{3}} \\
\mathrm{~S}_{44 \cdot 2 \mathrm{G}_{1}} \\
\mathrm{~S}_{44 \cdot 2 \mathrm{G}_{5}} \\
\mathrm{~S}_{44 \cdot 2} \mathrm{G} \\
\mathrm{S}_{44 \cdot 2} \mathrm{G}_{16} \\
\mathrm{~S}_{44 \cdot 2 \mathrm{G}_{1} 8}\end{array}$ & $\begin{array}{l}42 \\
32 \\
35 \\
29 \\
34 \\
42\end{array}$ & $\begin{array}{l}44 \\
41 \\
51 \\
55 \\
40 \\
44\end{array}$ & $\begin{array}{r}101 \\
93 \\
95 \\
92 \\
\text { 108 } \\
\text { 101 }\end{array}$ & $\begin{array}{l}187 \\
166 \\
181 \\
176 \\
182 \\
187\end{array}$ \\
\hline & Total & $2 \times 4$ & 275 & 590 & 1079 \\
\hline \multirow[t]{2}{*}{ Duplex } & $\begin{array}{l}\mathrm{S}_{44} \cdot 2 \mathrm{G}_{7} \\
\mathrm{~S}_{44} \cdot 2 \mathrm{G}_{9} \\
\mathrm{~S}_{44 \cdot 2} \mathrm{GIO} \\
\mathrm{S}_{44 \cdot 2 \mathrm{G}}\end{array}$ & $\begin{array}{r}9 \\
13 \\
9 \\
6\end{array}$ & $\begin{array}{l}68 \\
71 \\
72 \\
60\end{array}$ & $\begin{array}{r}95 \\
108 \\
108 \\
69\end{array}$ & $\begin{array}{r}172 \\
192 \\
189 \\
135\end{array}$ \\
\hline & Total & 37 & $27 x$ & $3^{80}$ & 688 \\
\hline \multirow[t]{2}{*}{ Triplex } & 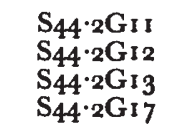 & $\begin{array}{l}3 \\
2 \\
3 \\
\ldots\end{array}$ & $\begin{array}{l}47 \\
64 \\
80 \\
79\end{array}$ & $\begin{array}{r}46 \\
110 \\
98 \\
70\end{array}$ & $\begin{array}{r}96 \\
176 \\
181 \\
149\end{array}$ \\
\hline & Total . & 8 & 270 & 324 & 502 \\
\hline
\end{tabular}

will be $\mathrm{I}-e^{-m}$. Among these latter the average number of Long plants observed must be $m /\left(1-e^{-m}\right)$. Actually the average number observed among the I I progenies classified as from triplex seed parents

TABLE 3

Double reduction in ovule formation

\begin{tabular}{|c|c|c|c|c|}
\hline Year grown & Progenies & $\mathrm{L}$ & $\mathbf{M}$ & Total \\
\hline \multirow[t]{2}{*}{$\begin{array}{l}\text { r } 942 \text { and } 1943 \\
\text { r } 945 . \\
1946 . \\
\text { r } 948 . \\
\text { r } 946-1951\end{array}$} & $\begin{array}{l}\text { M40.2F } \\
5 \text { Shorts } \\
4 \text { Shorts } \\
\text { 5 Shorts } \\
6 \text { Mids } \\
\text { S }_{45 \cdot 2}\end{array}$ & $\begin{array}{r}22 \\
12 \\
8 \\
16 \\
15 \\
5\end{array}$ & $\begin{array}{r}1053 \\
45^{2} \\
270 \\
4^{18} \\
45^{8} \\
267\end{array}$ & $\begin{array}{r}1075 \\
464 \\
278 \\
434 \\
473 \\
272\end{array}$ \\
\hline & Total . & $7^{8}$ & 2918 & 2996 \\
\hline
\end{tabular}

is $3 \mathrm{I} / \mathrm{II}$ or $2 \cdot \dot{8} \mathrm{i}$. This corresponds with an estimated $m$ of $2 \cdot 6 \mathrm{III} 4$ for which $e^{-m}$ is 0.07345 . The number of triplex progenies corresponding with I I observed is, therefore, I I $/ 0 \cdot 92655$, or I I 872 . If, therefore, 
we add $7 / 8$ of the average number of plants in a progeny, e.g. about 70 , to the number of plants not Long observed in the progenies, i.e. if we take an estimate based on 31 out of 977 instead of 31 out of 907 , we shall have made a reasonable allowance for the possibility that a triplex progeny has been excluded. The correction arrived at is so trifling, that more elaborate calculations are not necessary.

Another triplex, $\mathrm{S}_{45} \cdot 2$, was identified from a repetition in 1944 of the cross, $\mathrm{Ss}_{3} \mathrm{M}_{2} \mathrm{~m}_{2}=\mathrm{s}_{4} \mathrm{Mm}_{3}$, made the previous year. Progenies

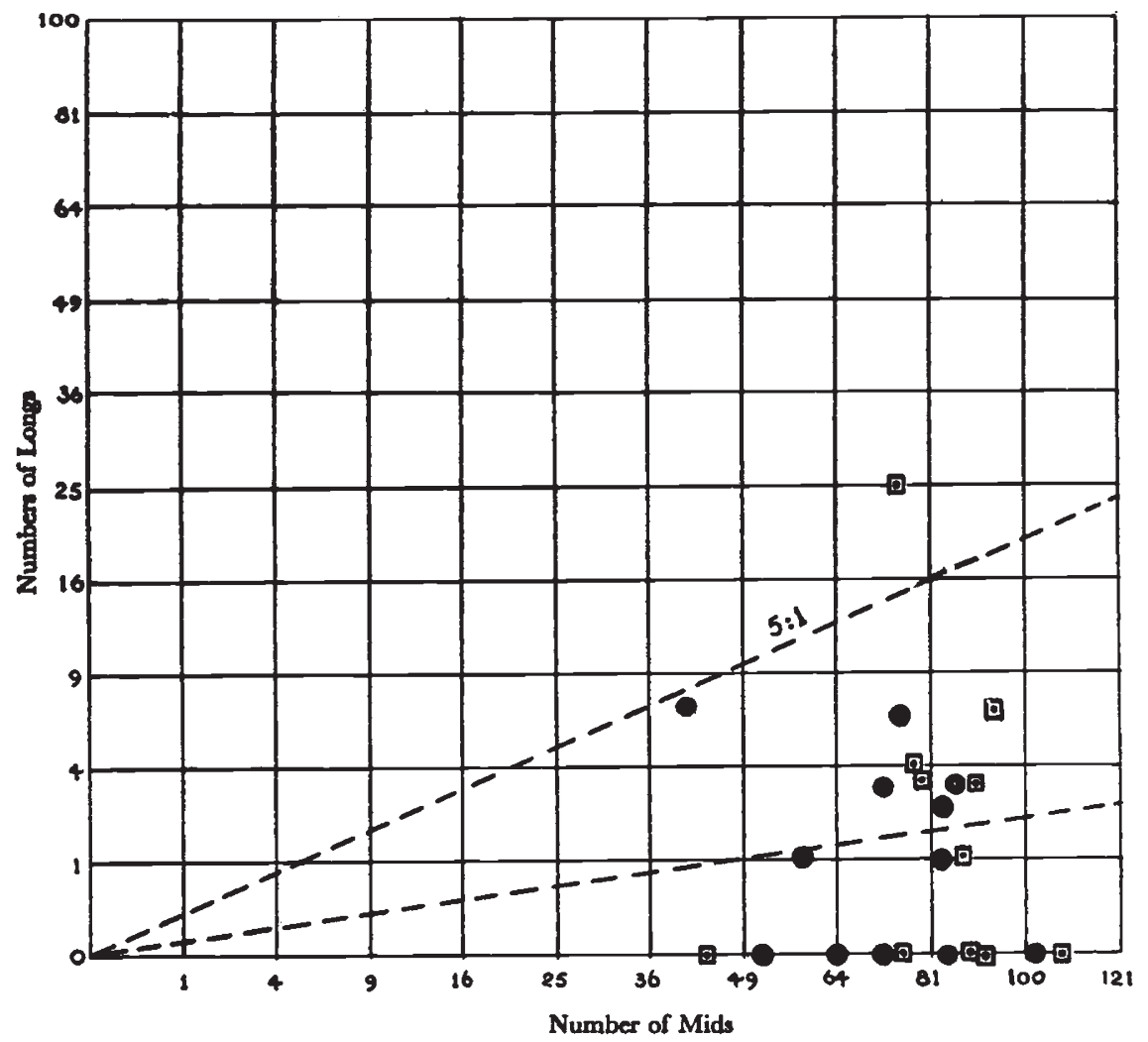

Progenies from to Shorts $\square$

Progenies from 12 Mids

FIG. 1.-1948 test progenies from $\mathrm{Ss}_{3} \mathbf{M}_{3} \mathrm{~m}=\mathrm{s}_{4} \mathbf{M}_{3} \mathrm{~m}$

from this plant have been grown repeatedly since then. The results are shown in the fifth line of table 3 , in which all the data bearing on ovule formation are summarised. The percentage of Longs in the progenies-2.6035 per cent. over all-represents a quarter of $\alpha$, the frequency of double reduction, in ovule formation, which is, therefore, estimated at 10.4I 4 per cent. If we include the allowance made on the 1948 progenies, the percentage of Longs is 2.544 , giving an estimate for $a=10 \cdot 176$ per cent. Both the crude and the corrected data are homogeneous. In the first case $\chi^{2}=4.393$ and in the second $\chi^{2}=3.304$ for 4 degrees of freedom. 


\section{SHORTS AND MIDS QUADRUPLEX FOR MID}

Amongst the plants tested in 1948, four Shorts and five Mids gave no Longs in their progenies (fig. I). Four of these plants, two Shorts and two Mids, were tested again in 1949 with larger progenies. The combined data from both years are given in table 4 .

TABLE 4

Test progenies from 2 Shorts and 2 Mids quadruplex for Mid

\begin{tabular}{|c|c|c|c|c|}
\hline Plan & L & $\mathbf{M}$ & $\mathrm{S}$ & Total \\
\hline $\begin{array}{l}\mathrm{S}_{47} \cdot 16 \\
\mathrm{~S}_{47} \cdot 23 \\
\mathrm{M}_{47} \cdot 8 \\
\mathrm{M}_{47} .12\end{array}$ & $\begin{array}{c}\ldots \\
\ldots \\
\ldots \\
\ldots\end{array}$ & $\begin{array}{l}552 \\
571 \\
546 \\
567\end{array}$ & $\begin{array}{c}575 \\
582 \\
\ldots \\
2\end{array}$ & $\begin{array}{r}1127 \\
1153 \\
547 \\
569\end{array}$ \\
\hline
\end{tabular}

The presence of two Shorts in the progeny of the Mid, M47.I2, must be due to stray pollen at the crossing plot or to contamination in the handling of the seeds, which are very small. The Long observed in the progeny of the other Mid must also be a contaminant, since, if this Mid were a triplex 15.65 Longs would be expected from 547 plants. It was, therefore, concluded that all four plants are quadruplex for mid.

\section{DOUBLE REDUCTION IN POLLEN FORMATION}

To obtain an estimate of $a$ in pollen formation it was necessary to use the triplex Mid as pollen parent and the recessive Long as seed parent. As demonstrated by Fisher and Mather (1943), the advantages of the technique of open pollination, which we have used for all tests in this investigation, far outweigh the disadvantage of the risk of contamination by foreign pollen, and they found this to be less than I per cent. in their progenies. It should be pointed out, however, that the risk of error in the estimate of double reduction due to the same percentage of foreign pollen is about fifty times greater when the seed parent is a Long than when it is a Mid or Short. This becomes apparent when it is realised that all the ovules from a Long will, if fertilised by pollen carrying neither mid nor short, increase the proportion of long-styled individuals in the progeny. Since calculation shows that 42 per cent. of such pollen exists in a theoretical population (Fisher, I94I), even 5 per cent. stray pollen at the crossing plot would almost double the percentage of Longs observed in the progeny. On the other hand, when the triplex Mid is the seed parent, only those ovules not carrying mid, that is about 2 per cent., can if fertilised by pollen carrying mid, result in a deficiency of Longs in the progeny, If 5 per cent. foreign pollen were present, the deficiency would be less than 0.05 per cent., a difference that could make no serious difference to the estimate of $a$. 
With this very real source of error in mind, great care was taken in 1948 to find a plot far from any known Lythrum populations for the pollination of a long-styled plant by the triplex Mid, $\mathrm{M}_{40} \cdot{ }_{2} \mathrm{~F}$. To make plenty of the right pollen available, the Mid was divided and planted in a ring round the Long. Seed taken from the Long was grown first in 1949 and again in 195 I. The data are given in table 5 .

TABLE 5

Double reduction in pollen formation

\begin{tabular}{|c|c|c|c|c|c|}
\hline \multicolumn{2}{|c|}{ Year } & $\mathbf{L}$ & $\mathbf{M}$ & $\mathrm{S}$ & Total \\
\hline 1949 & - & 10 & 374 & $\ldots$ & $3^{84}$ \\
\hline 1951 & $\cdot$ & 21 & 943 & $\ldots$ & 964 \\
\hline Total & . & $3^{x}$ & $\times 3 \times 7$ & $\ldots$ & $134^{8}$ \\
\hline
\end{tabular}

The percentage of Longs- $2 \cdot 300$ per cent.-is slightly less than that observed in ovule formation. This, and the fact that no Shorts were observed in either year, is convincing evidence that foreign pollen was absent at the crossing plot. The estimate of $a$ is 9.199 per cent. The data for both years are homogeneous- $\chi_{(\mathrm{z})}^{2}=0.2225 \%$

The data from all years, I943-I95I, from both ovules and pollen combined are homogeneous, $\chi^{2}=5 \cdot 1$ Io for 6 degrees of freedom, indicating that seasonal variations do not affect the frequency of double reduction. Taking the two estimates together we get $2 \cdot 509 \pm \cdot 237$ per cent. Longs and $a=10.037 \pm .949$ per cent., and $\chi^{2}=0.35$ I for I degree of freedom, on the crude data. If we include a twelfth progeny from the $194^{8}$ families, the percentage of Longs is $2 \cdot 469 \pm \cdot 234$ per cent., giving $a=9 \cdot 878 \pm \cdot 93^{6}$ per cent., and $\chi^{2}=0.232$ for $\mathrm{I}$ degree of freedom. Our estimate is only slightly higher than that forecast by Fisher and Mather in 1943.

I am much indebted to Professor Sir Ronald Fisher, not only for his constant guidance and help in every aspect of the work, but for supplying the material and suggesting the investigation.

\section{SUMMARY}

About the time when it was realised that the gametic output from polysomic organisms of various genotypes could be expressed in terms of a single parameter, viz. the frequency of double reduction, $a$, an attempt was first made to estimate this frequency at the mid locus in Lythrum salicaria. When Fisher and Mather (1943) established polysomic inheritance in $E$. salicaria, they obtained a triplex mid that could only have arisen by double reduction. This plant was backcrossed to the recessive long-styled form and in two seasons gave 22 Longs out of 1075. The proportion of Longs represents a quarter of $a$ in ovule formation, which was then estimated at $9 \cdot 18$ per cent. Similar 
data has been obtained in subsequent years. In 1948 triplex and quadruplex plants were distinguished only by their performance in producing or not producing Longs. Allowance has been made for the possibility that one or more triplex had been classified as a quadruplex by adding $7 / 8$ of the average number of plants in a progeny, 7o, to the Mids observed. The corrected total of 78 out of 3066 plants were obtained in five years. The proportion of Longs is 2.544 per cent. giving $a=10 \cdot 176$ per cent.

To obtain an estimate of $a$ in pollen formation the reciprocal cross was made in 1948 . In such a cross the risk of error from contamination by foreign pollen is about $5^{\circ}$ times greater than when the triplex plant is the seed parent. Since the open pollination technique was used throughout, special care was taken in selecting a site for the pollination plot for this cross. In two years 3 I Longs were obtained out of $134^{8}$ plants ; no Shorts were observed, thus providing evidence that foreign pollen was absent. The percentage of Longs is $2 \cdot 300$ per cent., giving an estimate of $a=9.199$ per cent. in pollen formation, very close to the value for ovules. Combining the data from ovules and pollen the proportion of Longs is $2 \cdot 469 \pm \cdot 234$ per cent., and $a=9 \cdot 878 \pm \cdot 936$ per cent. The data obtained from 1942 to $195^{\mathrm{I}}$ are homogeneous, $\chi_{(6)}^{2}=5.110$, indicating that $a$ is not affected by seasonal differences.

Of the Shorts and Mids likely to be quadruplex for mid, two of each type have been tested with adequate numbers and their genotype verified. All four were morphologically normal showing the completeness of dominance at the mid locus.

\section{REFERENCES}

BLAKESleE, A. F., BELling, J., AND FARnhaM, M. E. I923. Inheritance in tetraploid Daturas. Bot. Gaz., 76, 329-373.

DARlington, C. D. I929. Chromosome behaviour and structural hybridity in the Tradescantic. 7. Genet., 21, 207-286.

Darlington, C. D. I931. Meiosis in diploid and tetraploid Primula sinensis. 7 . Genet., 24, 65-96.

FISHER, R. A. I 941 . The theoretical consequences of polyploid inheritance for the mid style form of Lythrum salicaria. Ann. Eug., II, 31-38.

FISHER, R. A. I943. Allowance for double reduction in the calculation of genotype frequencies with polysomic inheritance. Ann. Eug., 12, I69-I 71.

FISHER, R. A. I 949. The linkage problem in a tetrasomic wild plant, Lythrum salicaria. Proc. 8th Int. Cong. Genetics, i 948, Hereditas suppl., pp. 223-233.

FISHER, R. A., AND MATHER, $\mathbf{k}$. I943. The inheritance of style length in Lythrum salicaria. Ann. Eug., 12, I-23.

haldane, J. B. S. 1930. Theoretical genetics of autqtetraploids. 7. Genet., 22, 359-372.

LAWRENCE, W. J. c. I929. The genetics and cytology of Dahlia species. F. Genet., $21,125^{-I} 5^{8}$.

LAWRENCE, W. J. C., AND SCOTT-MONCRIEFF, R. I935. The genetics and chemistry of flower colour in Dahlia : a new theory of specific pigmentation. $\mathcal{J}$. Genet., 30, $155-226$.

MATHER, x. 1936. Segregation and linkage in autotetraploids. 7. Genet., 32, 287-314. 